Research Article

\title{
Research on the Disaster-Inducing Mechanism of Coal-Gas Outburst
}

\author{
Fengxiang Nie, ${ }^{1}$ Honglei Wang $\mathbb{D}^{2},{ }^{2}$ and Liming Qiu $\mathbb{D}^{2,3}$ \\ ${ }^{1}$ School of Resources and Safety Engineering, China University of Mining and Technology (Beijing), Beijing 100083, China \\ ${ }^{2}$ School of Civil and Environmental Engineering, University of Science \& Technology Beijing, Beijing 100083, China \\ ${ }^{3}$ Guangxi Key Laboratory of Disaster Prevention and Engineering Safety, Guangxi University, Nanning 530004, China
}

Correspondence should be addressed to Honglei Wang; wang_hl007@163.com and Liming Qiu; qiulm@ustb.edu.cn

Received 25 July 2019; Revised 29 October 2019; Accepted 4 November 2019; Published 29 March 2020

Academic Editor: Antonio Formisano

Copyright (c) 2020 Fengxiang Nie et al. This is an open access article distributed under the Creative Commons Attribution License, which permits unrestricted use, distribution, and reproduction in any medium, provided the original work is properly cited.

In China, coal-gas outburst is seriously affecting safety of the coal mine. To improve the safety status of underground coal mining, this work investigated the evolution process and occurrence mechanism of coal-gas outburst under the coupling action of stress and gas. Results show that increasing either gas pressure or in-situ stress can make coal destroy and destabilize, and the contribution of gas pressure to coal failure is twice that of in-situ stress. In ultradeep coal mining, coal-gas outburst may occur even under the condition of low gas pressure due to large in-situ stress. Moreover, the larger the mining depth is, the lower the gas index is required for disaster occurrence. The results have certain guiding significance for coal energy mining and the control of coal-gas outburst in deep coal mining.

\section{Introduction}

With the development of society, people's demand for mineral resources has gradually increased, and coal mining has gradually shifted to the deep part of the earth, leading to more and more dynamic disasters during the production, which poses a threat to the safety of energy and miners' lives $[1,2]$. In recent years, with the increase of mining depth, coal and gas outburst disasters have begun to occur in some low gas mines, which contradicts previous research experience. This indicates that with the increase of mining depth, the mechanical properties of deep coal and rock have changed, and the mechanism of coal and gas outburst is different from that of shallow coal. The mechanism of coal and gas outburst in deep mining and low-gas condition is an urgent problem to be studied $[3,4]$.

The occurrence of coal dynamic disasters is mainly because of coal destabilization and failure caused by the gestation, development, propagation, and coalescence of microcracks. When coal and rock mass are damaged under load, different kinds of primary cracks gradually expand and penetrate. Rock failure caused by crack growth is an important subject in rock mechanics research. Many scholars have performed a lot of research on the law of crack propagation in coal and rock. In the early $20^{\text {th }}$ century, scholars have started to explore the production and propagation of cracks [5], and comprehensive experimental studies on the interaction of the gestation and development of cracks in rocks began in the middle of the last century and have achieved rich progresses [6-8]. Research results show that, under compressive load, the development of cracks, existing and newly gestated due to ground pressure inside rocks, first from the tips of these cracks and gradually propagate in the direction parallel to compressive direction [9]. When the cracks are short, their propagation is mainly under the control of the local stress field. With their expansion, they interact with adjacent microcracks, resulting in crack coalescence and eventual rock failure [10].

Studies on the mechanical properties and cracking behaviors of a single crack in the conditions of both dynamic and quasi-static strain rates have shown that shear cracks are dominant in the action of dynamic load while tensile cracks are dominant in the action of quasi-static load [11-16] In our 
work, we observed three different types of cracks and believed that the fracturing processes of opened and closed cracks are similar and the friction along the crack direction strengthens the cohesion of coal, which are conducive to the coalescence of shear cracks. cracks' gestation and coalescent stresses, which are conducive to the coalescence of shear cracks.

In recent years, with the mining depth ever increasing, dynamic disaster manifested that themselves in the deep coal seams with low gas frequently. Under the complex environment of deep coal seam, coal is subjected to larger tectonic stress. Under the influence of mining or other disturbance, internal microcracks of coal undergo gestation, development, and coalescence, lead to the dynamic disasters, such as extensive roof and floor fractures, rock burst, coal and gas outburst, and others. Therefore, the occurrence of deep coal and rock dynamic disasters is the result of instability failure of gas-bearing coal under the combined action of high stress and gas. Many researchers, from the aspects of coal cracks gestation and propagation as well as the fracture mechanics, massively studied coal and gas outbursts and similar dynamic disasters are caused by coal destabilization. Qiu et al. [17] found that coal crack had fractal characteristics by comparing the photos of crack development in the process of coal failure under load. $\mathrm{Li}$ et al. [18] determined the physical laws that govern crack propagation in coal, a fracture mechanics model. Pre-existing cracks tend to branch towards the damage in the coal matrix while induced fractures tend to connect with other cracks nearby. According to crack propagation, the abutment pressure area in an underground mine was divided into six zones and the field data are consistent with the theoretical and experimental results. Kong et al. [19] studied the dynamic mechanical characteristics and the fracture mechanism of gas-bearing coal based on SHPB experiments and found that gas-bearing coal can produce more cracks under impact load. Zhao et al. [20], based on the theories of coal spherical shell failure, coal spallation, and coal powder pneumatic conveying, studied the flow state and transport mechanism of coal and gas outbursts. Chai et al. [21] comprehensively considered crack gestation and propagation evolution under both compressive and tensile shear stresses and introduced the initial damage tensor of cracks and the additive damage tensor after crack gestation and propagation into their user-defined constitutive model. Zuo et al. [22] separately established the axial crack closure model and the axial crack propagation model to study the variation characteristics of axial cracks with stress and strain. Zhao et al. [23] used a 3D mesoscopic monitoring software for dynamic evolution of the coal surface microstructure as the main research equipment to examine the propagation law of cracks on the coal surface under impact load. He and Wang [24] further analyzed the general law of the deformation and failure process of a composite from the aspects of both damaged crack evolution process and the mechanics of interactions of different media. Xie et al. [25] theoretically analyzed the role of mining the released coal seam in preventing coal and gas outburst based on the basic theory of fracture mechanics and further proposed a new method for preventing coal and gas outburst from both aspects of reducing the coal's stress intensity factor and improving the fracture toughness. Wang et al. [26] found the mechanical genesis of stress concentration at crack tips from the angle of fracture mechanics and believed that rock (coal) and gas outburst is a dynamic phenomenon in which cracks fall in instability and failure when the stress intensity factor at crack tips reaches the fracture toughness of the rock.

Fedorchenko and Fedorov [27] consider the nonstationary, equilibrium velocity approach of the nonuniform environment mechanics and solved the coal and gas outburst problem. Zhao et al. [20] used the gas-solid plug flow formation analysis to propose a new view of the gasdistributed process as a reciprocating air knife of high pressure that cuts the ejected coal powders. Gao [28] studied the mechanism of coal and gas outburst in Shimen uncovering coal under the influence of the structure. Through laboratory simulation and numerical calculation, it was found that stress concentration in the process of protrusion induced by coal in the fault area under compressive stress increased the elastic potential of the coal body, and the gas caused the coal body to be unstable and thrown. Xu et al. [29] believed that coal and gas outburst are caused by the microelement destruction of coal and gas and thus constructed a coal-rock microelement model to analyze the damage of the coal-rock microbody region and the generation of protruding regions. Zhang [30] analyzed the dynamic mechanical characteristics of coal, the energy dissipation characteristics under dynamic load, and the effect of dynamic load on coal and gas outburst through various research methods and concluded that the combined effect of the sudden load input energy and the gas expansion energy leads to coal and gas outburst. Wang et al. [31] analyzed the effects of different stresses on coal and gas outbursts. It is believed that the in-situ stress can affect the outburst by affecting the gas emission intensity. However, under the conditions of deep high stress and low gas, the research on the influence of geostress and gas pressure on coal and rock dynamic disasters is rarely reported.

The process of damage and disaster evolution of coal and rock is extremely complex. Especially, the study of crack initiation, development, and structural instability fracture of gas-bearing coal and rock under stress-gas action in deep mine is insufficient. There is no consensus on the mechanism of coal and rock dynamic disasters in deep mining, especially on the mechanism of low-index outburst disasters. This is of great practical significance for the prevention and control of gas disasters under deep mining. According to the theory of rock fracture mechanics, we first analyze the types of crack growth and stress intensity factors of coal and rock. Then, based on the theory of strain energy density factor, the influence of in-situ stress, gas pressure, and physical and mechanical properties of coal on the internal crack growth of the coal body is studied. Finally, the mechanism of coal body failure and outburst occurrence at the working face is discussed and analyzed. Our conclusions can provide a theoretical basis for more accurate prediction of coal and gas outburst and more reasonable determination of predictive indicators.

\section{Analysis on Crack Propagation in Gas- Bearing Coal under Load}

2.1. Analysis of Crack Initiation Conditions of Coal and Rock Containing Gas. Irwin [32] divided simple cracks into three 
types, as shown in Figure 1. Type I crack is open cracks, which means that under tensile stress perpendicular to the crack surface, the crack surface moves in the direction perpendicular to itself. Both Type II and Type III cracks are shear cracks, of which Type II cracks slip along the direction parallel to the crack strike, while Type III cracks slip along the direction perpendicular to the crack strike.

Feng [33] studied the stress distribution characteristics of the surrounding rock in the coal roadway and pointed out that in a certain range of roadway lateral displacement, the vertical stress of coal increases and the horizontal stress continues to decrease. The difference between the two will continue to increase. The surrounding rock gradually changed from three-way compression to only two-way compression, the stress balance state will be broken, and the deformation failure would occur. The research results of Wang et al. [34] show that the characteristics of coal macromeso mechanical coupling failure and instability under uniaxial compression are consistent with the results of FLAC3D numerical simulation and the damage of coal observed in the field which will further explain how to simplify the failure process of coal on the coal wall in front of the working face to the problem of uniaxial compression. The vertical in-situ stress $\sigma_{m}$ of deep seam is far greater than the minimum principal stress $\sigma_{3}$. The stress state of the coal at the coal wall in front of the working face can be simplified into a uniaxial compression problem of the ground stress $\sigma_{m}$. Figure 2(a) shows the state of stress on the characteristic unit of the cracked coal, REV. From the figure, REV subjects to the uniaxial compression by $\sigma_{m}$ and contains a crack with a length of $2 \mathrm{a}$ and an angle of $0<\alpha<\pi / 2$ to the direction of the maximum principal stress. The crack contains free gas with a pressure of $P_{0}$. Because a large amount of adsorbed gas in the coal matrix will be desorbed in the form of free gas in the process of crack growth; the free gas pressure of $P_{0}$ will remain unchanged in the process of crack growth.

For the ground stress $\sigma$ of the coal body at the coal wall in front of the face, we decompose it into a pair of normal stress $\sigma_{x}$ and $\sigma_{y}$ and a pair of shear stress $\tau_{x y}$ and $\tau_{y x}$. The long-axis direction of the crack is $Y$-axis and the short axis direction is $X$-axis. The equilibrium of normal stress $\sigma_{y}$ and shear stress $\tau_{x y}$ on the crack tip in the $y$-axis direction shows that the normal stress $\sigma x$ - $p$ and the shear stress $\tau_{y x}$ in the $x$-axis direction are the main factors that cause the crack growth. When the crack surface is closed by pressure, i.e., $\sigma_{x}>P$, there is friction distribution on the crack surface, and the crack growth belongs to type II crack growth. The paper analyzes the influence of friction on $K_{\mathrm{II}}$ in formula (4). Generally, the fracture width of the coal body is millimeter or even nanometer, which is very small compared with the coal seam size. Therefore, in the analysis of the influence of the friction force generated by the decomposed normal stress on the crack growth, the friction force is equivalent to the uniform shear force in the infinite far field. Figure 2(b) shows the stress state of an elliptical crack in the Cartesian coordinate system set with its short and long axis directions corresponding to the $x$-and $y$-axis. The singular term of the stress component at the crack front in the polar coordinates is expressed as follows:

$$
\left\{\begin{array}{l}
\sigma_{\pi}=\frac{1}{2 \sqrt{2 \pi r}}\left[K_{I}\left(\cos \frac{\theta}{2}(3-\cos \theta)\right)+K_{I I}(3 \cos \theta-1) \sin \frac{\theta}{2}\right] \\
\sigma_{\theta \theta}=\frac{1}{2 \sqrt{2 \pi r}} \cos \frac{\theta}{2}\left[K_{I}(1+\cos \theta)+3 K_{I I} \sin \theta\right], \\
\tau_{r \theta}=\frac{1}{2 \sqrt{2 \pi r}} \cos \frac{\theta}{2}\left[K_{I} \sin \theta+K_{I I}(3 \cos \theta-1)\right],
\end{array}\right.
$$

where $K_{\mathrm{I}}$ and $K_{\mathrm{II}}$ are the stress intensity factors of Type I and II cracks, respectively.

Set $h=P_{0} / \sigma_{m}$, and the equivalent normal stress, $\sigma_{N}$, on the surface of the crack inside the loaded gas-bearing coal is

$$
\sigma_{N}=P_{0}-\sigma_{m} \sin ^{2} \alpha=\sigma_{m}\left(h-\sin ^{2} \alpha\right) .
$$

Analysis of equations (1) and (2), one can find that

(1) When $h \leq \sin ^{2} \alpha$, the gas pressure is less than the normal stress of the ground stress in the long-axis direction of the crack. Under the stress, the crack surface has to close, leading to crack closure and friction distribution on the crack surface. The crack propagation is a type II propagation with the equivalent shear stress on the crack surface, and $\tau_{e}$ can be computed by the following formula:

$$
\tau_{e}=\sigma_{m}\left[\sin \alpha \cos \alpha+f_{\mathrm{d}}\left(h-\sin ^{2} \alpha\right)\right]
$$

where $f_{\mathrm{d}}$ is the friction coefficient of the crack tips and $\tau_{e}>0$. The stress intensity factor of the crack is

$$
\begin{aligned}
K_{I} & =0 \\
K_{I I} & =\sigma_{m}\left[\sin \alpha \cos \alpha+f_{\mathrm{d}}\left(h-\sin ^{2} \alpha\right)\right] \sqrt{\pi a}
\end{aligned}
$$

Set $M=\sqrt{a / 2 r}$ and inserting equation (4) into equation (1) finds the circular stress as follows:

$$
\sigma_{\theta \theta}=\frac{3}{2} M \sigma_{m} \cos \frac{\theta}{2} \sin \theta\left[\sin \alpha \cos \alpha+f_{\mathrm{d}}\left(h-\sin ^{2} \alpha\right)\right] .
$$

(2) When $h>\sin ^{2} \alpha$, that is, the gas pressure is greater than the normal stress of the ground stress in the direction of the crack's long axis. The friction on the crack surface caused by the normal stress equals zero, and the equivalent shear stress, $\tau_{e}$, on the crack surface is

$$
\tau_{e}=\sigma_{m} \sin \alpha \cos \alpha
$$

The stress intensity factor of the crack is

$$
\begin{aligned}
K_{I} & =\sigma_{m}\left(h-\sin ^{2} \alpha\right) \sqrt{\pi a}, \\
K_{I I} & =\sigma_{m} \sin \alpha \cos \alpha \sqrt{\pi a} .
\end{aligned}
$$

Putting equation (7) into equation (1), find the circular stress as follows: 


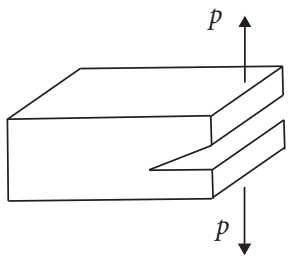

(a)

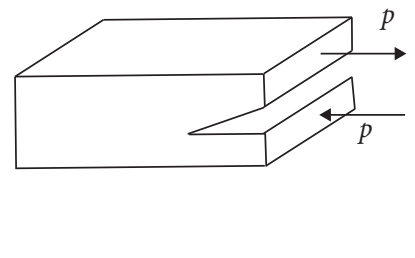

(b)

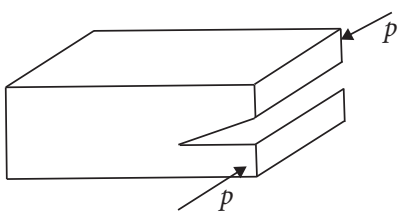

(c)

Figure 1: Three basic types of cracks Anderson [3]. (a) Type I. (b) Type II. (c) Type III.

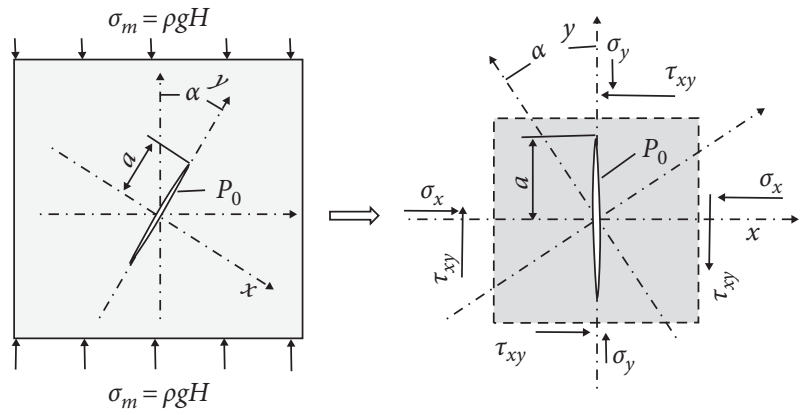

FIgURE 2: Stress state of cracks in front of the working face.

$$
\sigma_{\theta \theta}=\frac{1}{2} M \sigma_{m} \cos \frac{\theta}{2}\left[(1+\cos \theta)\left(h-\sin ^{2} \alpha\right)+3 \sin \alpha \cos \alpha \sin \theta\right] .
$$

Erdogan and Sih [35], based on their experimental observations, proposed the maximum circular tensile stress criterion and applied the maximum circular stress theory to explain the cracking initiation of two-dimensional Type I, Type II, and Type I-II composite cracks. The criterion holds that if a crack propagates in the direction $\theta$ corresponding to $\sigma_{\theta \theta \max }$, the direction satisfies the following conditions:

$$
\frac{\partial \sigma_{\theta \theta}}{\partial \theta}=0, \quad \frac{\partial \sigma_{\theta \theta}}{\partial \theta}<0
$$

The maximum circular stress theory holds that the crack propagation initiates when $\sigma_{\theta \theta \max }$ meets the following condition:

$$
\sigma_{\theta \theta}=\left.\right|_{\theta=\theta_{0}}=\sigma_{\theta \theta \max }>\sigma_{\mathrm{c}} .
$$

Equation (10) is the so-called initiation condition of crack propagation inside the loaded gas-bearing coal.

For closed cracks, the stress intensity factor is obtained from formula (4), while for the nonclosed crack, the stress intensity factor is obtained from formula (7). It can be seen from formulas (4) and (7) that the first part of the stress intensity factor $K_{\mathrm{II}}$ of the type II closed crack is the same as that of the type II nonclosed crack and is related to the shear stress $\tau_{y x}$ decomposed by the ground stress in the axial direction of the crack. The combined force of the normal stress decomposed from the ground stress in the direction of short axis and gas is related to the stress intensity factors $K_{\mathrm{II}}$ of closed crack and $K_{\mathrm{I}}$ nonclosed crack.
2.2. Analysis of Crack Propagation Type. Utilizing the values of stresses applied on the crack surface, $\tau_{x y}$ and $\sigma_{N}$, one can divide the crack propagation in the loaded gas-bearing coal into three types: Type I, Type II, and Type I-II composite cracks. Figure 3 shows the stress state and crack propagation type on the crack surface.

(1) When $h \leq \sin 2 \alpha, \tau_{e}=0$ and the crack direction $\alpha=\pi / 2$ and $h \leq 1, \tau_{x y}=0, \sigma_{N} \leq 0$, that is, the gas pressure is less than the ground stress, the horizontal crack has $K_{I}=0$ and $K_{I I}=0$. Thus, the crack surface is closed under the stress and there is a crack disturbing stress in the matrix.

(2) When the crack direction $\alpha=0$ and $\alpha=\pi / 2$ and $h>1$, $\tau_{x y}=0, \sigma_{N}>0$, that is, the vertical crack, or the horizontal crack at the time when gas pressure is greater than the ground stress, the crack has $K_{I} \neq 0$ and $K_{I I}=0$. Thus, the crack propagation belongs to Type I, and the crack starts to expand if it meets the maximum circular stress cracking condition, i.e., $\partial \sigma_{\theta \theta} / \partial \theta=0$ and $\partial \sigma_{\theta \theta} / \partial \theta<0$, from which, it follows

$$
\theta_{0}=0 \text {. }
$$

Thus, the second-order partial derivative of $\sigma_{\theta \theta}$ with respect to $\theta$ is bigger than zero, which is the solution to this problem. Putting equation (11) into equation (5), we find the maximum circular stress as follows:

$$
\sigma_{\theta \theta \max }=M \sigma_{m}\left(h-\sin ^{2} \alpha\right) \text {. }
$$

(3) When $h \leq \sin ^{2} \alpha, \sigma_{x y} \neq 0, \sigma_{N} \leq 0$, and the oblique crack has $K_{I}=0$ and $K_{I I} \neq 0$, the gas pressure is less than the normal stress of the ground stress in the long axis direction of the crack. Thus, the crack surface is subjected to stress and the crack in its expanding process will produce a friction against crack propagation. The crack propagation belongs to Type II, and the crack that begins to expand needs to meet the maximum circular stress cracking condition, i.e., $\partial \sigma_{\theta \theta} / \partial \theta=0$ and $\partial \sigma_{\theta \theta} / \partial \theta<0$, from which it follows

$$
\theta_{0}=\arccos \frac{1}{3}=-70.53^{\circ} \text {, }
$$

where $\theta=-\arccos (1 / 3)$ can make the second-order partial derivative of $\sigma_{\theta \theta}$ with respect to $\theta$ bigger than zero. Thus, $\theta=-\arccos (1 / 3)$ is the solution to this problem. Inserting 


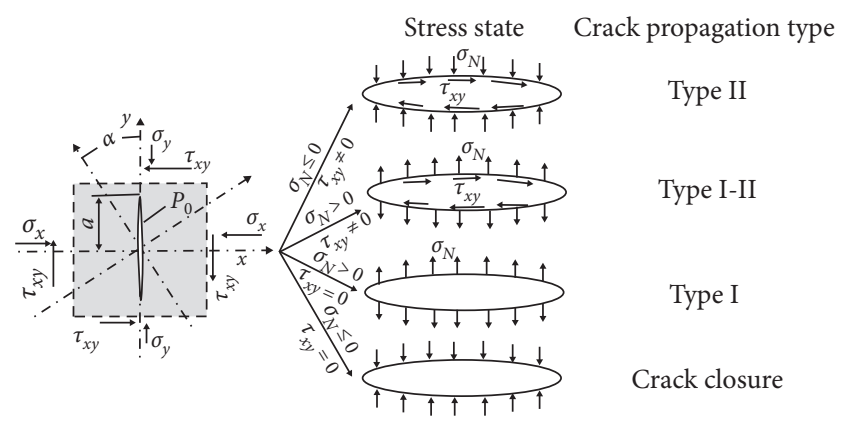

FIGURE 3: Crack stress state and crack propagation type.

equation (13) into equation (5), we find the maximum circular stress:

$$
\sigma_{\theta \theta}=\frac{2}{\sqrt{3}} M \sigma_{m}\left[\sin \alpha \cos \alpha+f_{\mathrm{d}}\left(h-\sin ^{2} \alpha\right)\right] .
$$

(4) When $h>\sin 2 \alpha, \tau_{x y} \neq 0$, and $\sigma_{N}>0$, that is, the gas pressure greater than the normal stress of the ground stress in the long axis direction of the crack and the oblique crack has $K_{I} \neq 0$ and $K_{I I} \neq 0$. Thus, the crack that begins to propagate needs to satisfy the maximum circular stress rupture condition, that is, $\partial \sigma_{\theta \theta} / \partial \theta=0$ and $\partial \sigma_{\theta \theta} / \partial \theta<0$, from which one finds

$$
\cos \frac{\theta}{2}\left[K_{I} \sin \theta+K_{I I}(3 \cos \theta-1)\right]=0 .
$$

The solution that makes the abovementioned equation be of physical significance is

$$
\theta_{0}=-2 \operatorname{acrtan} \frac{\sqrt{1+8\left(K_{I I} / K_{I}\right)^{2}-1}}{4\left(K_{I I} / K_{I}\right)} .
$$

Inserting equations (7) and (16) into equation (5), we find the maximum circular stress to be

$$
\begin{aligned}
\sigma_{\theta \theta \max }= & \frac{1}{2} M \sigma_{m} \cos \frac{\theta_{0}}{2}\left[\left(1+\cos \theta_{0}\right)\left(h-\sin ^{2} \alpha\right)\right. \\
& \left.+3 \sin \alpha \cos \alpha \sin \theta_{0}\right] .
\end{aligned}
$$

From equations (12), (14), and (17), clearly, the circular stress at the crack tips of the loaded gas-bearing coal is the function of the crack angle, $\alpha$, and the relationship between the maximum circular stress at the crack tips and the crack angle is shown in Figure 4.

It can be seen from Figure 4 that the maximum circular stress at the crack tips shows a trend of increase before decrease with the increase of the angle between the crack direction and its maximum principal stress. According to the maximum circular stress criterion, when the maximum circular stress at the crack tip, $\sigma_{\theta \theta}$, is greater than the tensile strength of the coal body, $\sigma_{c}$, the crack of the coal body begins to expand, that is, for a certain stress state, if the presence of $\alpha_{\max }$ and $\alpha_{\text {min }}$ makes the crack angle $\alpha$ satisfy $\alpha_{\max }<\alpha<\alpha_{\min }$, and the crack propagation starts.

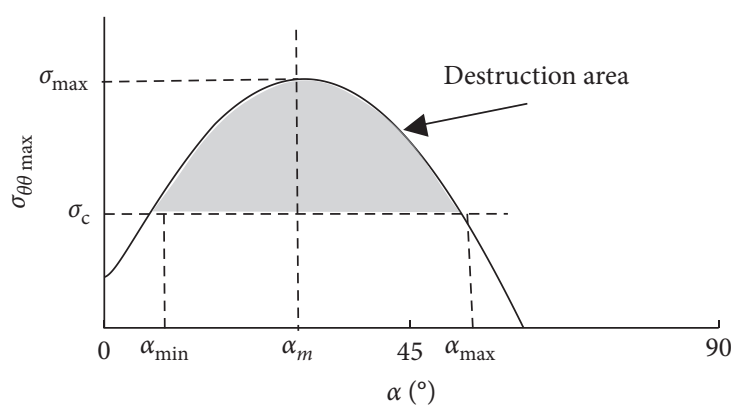

FIgURE 4: Relationship between circular stress at the crack tip and crack angle.

\section{Process Analysis of Dynamical Disasters due to Gas-Bearing Coal Fracture}

\subsection{Analysis of Factors Influencing Maximum Circular Stress on Loaded Gas-Bearing Coal}

3.1.1. Effect of Ground Stress on Maximum Circular Stress. At gas pressure $P=1 \mathrm{MPa}$ and the friction coefficient $f_{\mathrm{d}}=0.6$, the relationship of the circular stress at the crack tips in the loaded gas-bearing coal to the ground stress is shown in Figure 5(a). From the figure, it is clear that the circular stress keeps constant at different ground stresses when the crack angle is $0^{\circ}$. As the angle increases, the circular stress begins to increase. When the angle reaches $29.4^{\circ}$, the circular stress simultaneously reaches its peaks. At this time, the circular stress corresponding to $\sigma_{m}$ of $5 \mathrm{MPa}, 10 \mathrm{MPa}$, $15 \mathrm{MPa}$, and $20 \mathrm{MPa}$ is $2.33 \mathrm{MPa}, 3.96 \mathrm{MPa}, 5.60 \mathrm{MPa}$, and 7.23 MPa, respectively. When the angle further enlarges, the circular stress shows a tendency to decrease. When the angle is $58.8^{\circ}$, the stress remains the same. When the angle is greater than $58.8^{\circ}$, the lower the ground stress, the higher the circular stress. Data fitting finds that the maximum circular stress is positively correlated to the ground stress, which can be expressed as $\sigma_{\theta \theta \max }=0.3269 \sigma_{m}+0.6928$, as shown in Figure 5(b).

3.1.2. Effect of Gas Pressure on the Maximum Circular Stress. When the ground stress $\sigma_{m}=10 \mathrm{MPa}$ and the friction coefficient $f_{\mathrm{d}}=0.6$, the relationship of the circular stress at the tips of cracks in the loaded gas-bearing coal to gas pressure is shown in Figure 6(a). From the figure, it is clear that when the crack angle is $0^{\circ}$, the maximum circular stress equals to the gas pressure, and as the angle increases, the circular stress begins to increase. When the gas pressure is at $0 \mathrm{MPa}$, 0.5 $\mathrm{MPa}, 1.5 \mathrm{MPa}$, and $3.0 \mathrm{MPa}$, the angle $\alpha_{m}$ corresponding to the maximum circular stress of $3.27 \mathrm{MPa}, 3.62 \mathrm{MPa}$, $4.31 \mathrm{MPa}$, and $5.28 \mathrm{MPa}$ is $28.7^{\circ}, 28.9^{\circ}, 30.2^{\circ}$, and $32.1^{\circ}$, respectively. When the angle further grows, the circular stress shows a downward trend. Data fitting finds that the maximum circular stress is positively correlated with the ground stress, which can be expressed as $\sigma_{\theta \theta}=0.6761 P+3.2772$, as shown in Figure 6(b). The maximum circular stress has linear relationship with both ground stress and gas pressure, and the corresponding proportion coefficient are 0.3269 and 


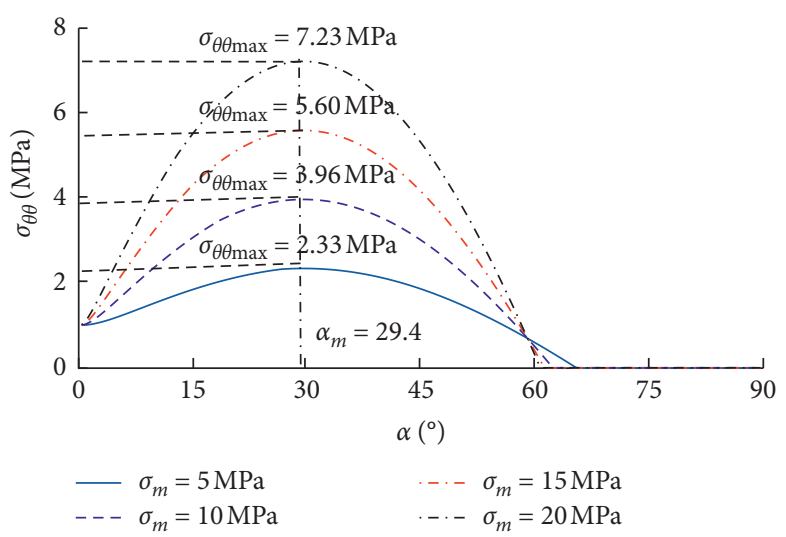

(a)

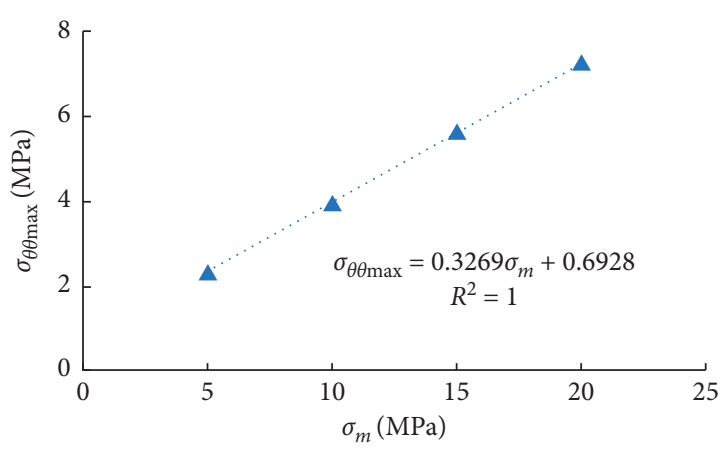

(b)

Figure 5: Effect of ground stress on maximum circular stress.



(a)



(b)

Figure 6: Effect of gas pressure on maximum circular stress.

0.6761 , respectively. In other words, the destructive power of increasing the same gas pressure to the coal is about twice of that of increasing the ground stress. The maximum circular stress has a negative power function correlation with the friction coefficient. Therefore, the main factor affecting the maximum circular stress is the gas pressure of cracks inside the coal seam. At high ground stress, smaller gas pressure can lead to coal failure.

\subsubsection{Effect of Friction Coefficient on the Maximum Circular} Stress. Figure 7 (a) shows the relationship of the circular stress at the tips of cracks in the loaded gas-bearing coal to the friction coefficient at ground stress $\sigma_{m}=10 \mathrm{MPa}$ and gas pressure $P=1 \mathrm{MPa}$. From Figure $7(\mathrm{a})$, it is evident that when the crack angle is less than $20.4^{\circ}$, the crack propagation belongs to Type I-II composite. At this time, the maximum circular stress is independent of the friction coefficient. When the crack angle is greater than $20.4^{\circ}$, the maximum circular stress reduces with the friction coefficient increasing. When the friction coefficient is $0,0.4,0.6$, and 0.8 , the angle $\alpha_{m}$ corresponding to the maximum circular stress of
5.77 $\mathrm{MPa}, 4.37 \mathrm{MPa}, 3.96 \mathrm{MPa}$, and $3.70 \mathrm{MPa}$ is $45^{\circ}, 34.5^{\circ}$, $29.4^{\circ}$, and $25.8^{\circ}$, respectively, and when the angle further increases, the circular stress shows a decreasing trend. Data fitting finds that the maximum circular stress is positively correlated to the ground stress, which can be expressed as $\sigma_{\theta \theta \max }=5.4679 \exp \left(-0.422^{*} f_{\mathrm{d}}\right)$, as shown in Figure $7(\mathrm{~b})$.

\subsection{Mechanism of Dynamic Disaster Evolution in Gas-Bearing Coal Seam}

3.2.1. Analysis of Coal Fracture Process in Front of Working Face. A change in the state of stress inside a coal in front of the working face will in turn cause a change in both fracture and gas fields [36], as shown in Figure 8. Under the mining disturbance, the coal in front of the working face undergoes three stages, namely, elastic stress stage or stage I, ground stress and gas pressure failure stage or stage II, and gastearing coal stage or stage III [37]. In the stage I, as the working face advances, the two mutually perpendicular tangential stresses increase continuously and the radial stress decreases ceaselessly. During this time, the coal under their 


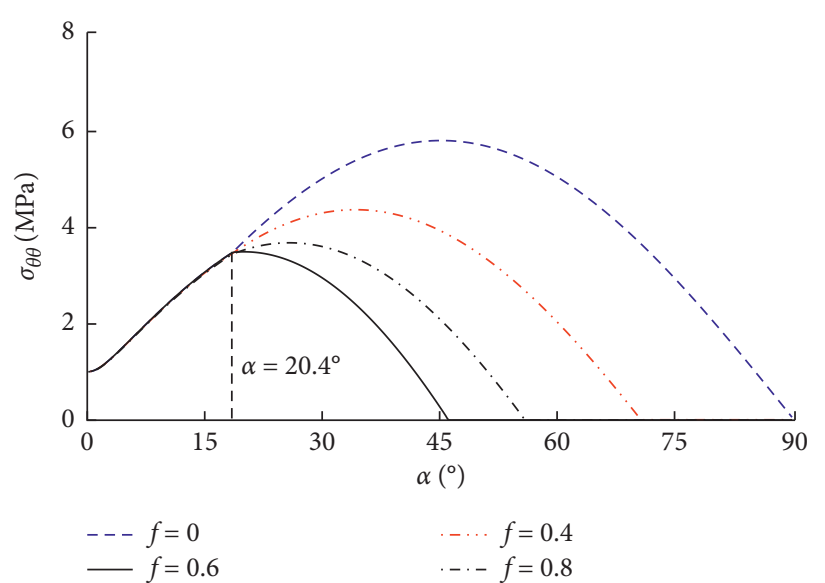

(a)

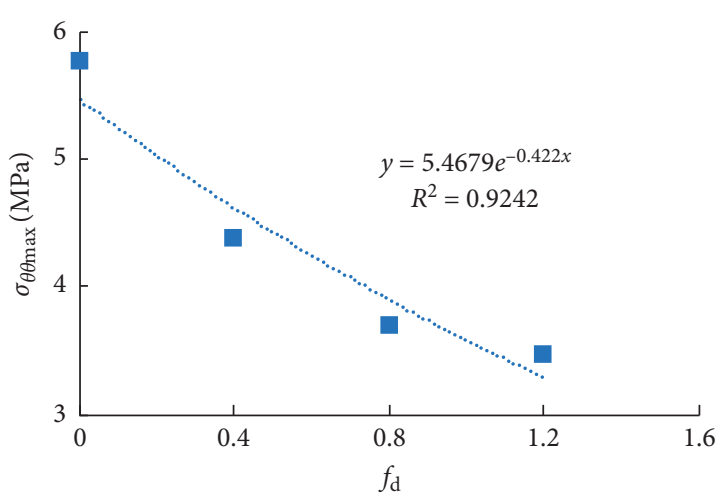

(b)

FIgURE 7: Effect of the friction coefficient on maximum circular stress.

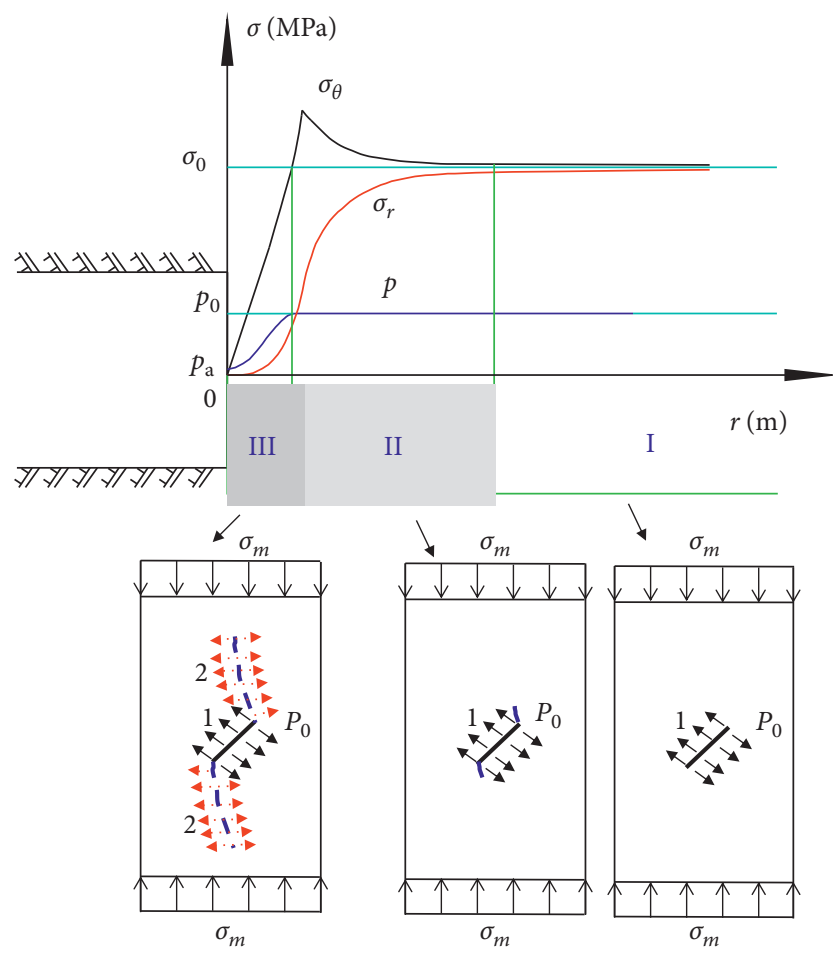

Figure 8: The stress state of coal in front of the working face.

actions is still in the elastic stress stage. When the tangential stress constantly increases and the radial stress continually reduces, the critical condition of crack growth is reached under the action of ground stress and gas pressure. Some of the cracks begin to expand, thus, part of the coal undergoes fracture, and the front of the working face enters the ground stress and gas pressure damage stage or stage II. Under the joint action of ground stress and gas pressure, the cracks inside the gas-bearing coal propagate and the presence of gas in the coal accelerates both tensile and shear damages of coal. Thus, coal is very prone to rapid crack expansion and the front of the working face enters gas-tearing coal (III) stage. After crack propagation, from equations (12), (14), and (17), clearly, the ability of gas pressure to break the coal body is positively proportional to the square root of the crack length $a$, and the asymptote of crack expansion orients toward the direction of the maximum principal stress, as shown in Figure 8. The ground stress-induced tensile force $\sigma_{\theta \theta}$ gradually decreases, and the gas effect gradually strengthens in the later stage of coal crack propagation.

A shallow mine has smaller ground stress, thus it is necessary to combine with higher gas pressure so as to initiate crack propagation in coal [38]. Coal fracturing requires greater gas pressure to do work, that is, it needs higher gas pressure. When coal mining extends to the deep part of coal mines, the larger ground stress can initiate crack propagation, and the crack length can be extended to be longer. The capacity of the gas pressure to break the coal increases rapidly with crack expansion. Although it is also possible to crack coal under the action of lower gas pressure, the gas threshold to initiate dynamic phenomenon reduces.

3.2.2. Deep Stress-Gas Disaster Evolution Process. The geological conditions of mines with dynamic disasters are generally complex. Gao et al. [39], Song and Zhang [40], Jia et al. [41], Li et al. [42], and Qiu et al. [43] have studied the influence of faults, folds, and other geological structures on coal and gas outburst. The former research results show that in the abnormal geological structure, under the disturbance of mining, it can produce greater unbalanced force. In the deep mine, this kind of unbalanced stress phenomenon is more intense. Under the action of large unbalanced stress and gas pressure, the coal body breaks, and the unstable failure causes the coal-rock dynamic disaster. The evolution process of the disaster is shown in Figure 9.

(1) Gestation stage: this stage experienced a series of events as the natural sedimentary formation, geological structure, and mining process of coal mass. The existence of geological structures such as faults affects the distribution of stress in the coal and changes its physical and mechanical properties, and 


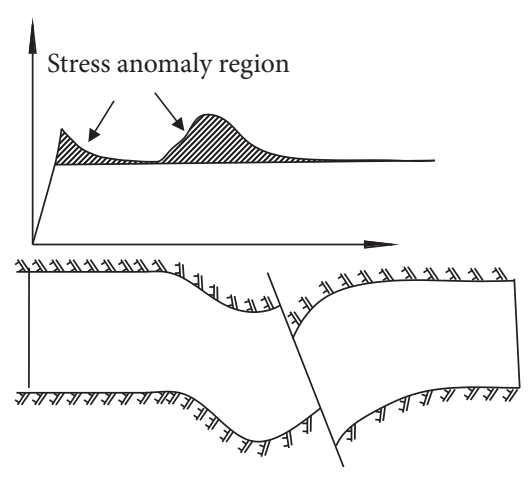

(a)

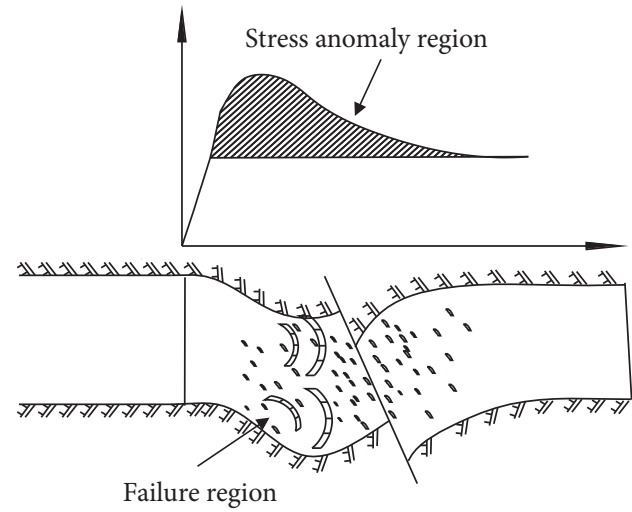

(c)

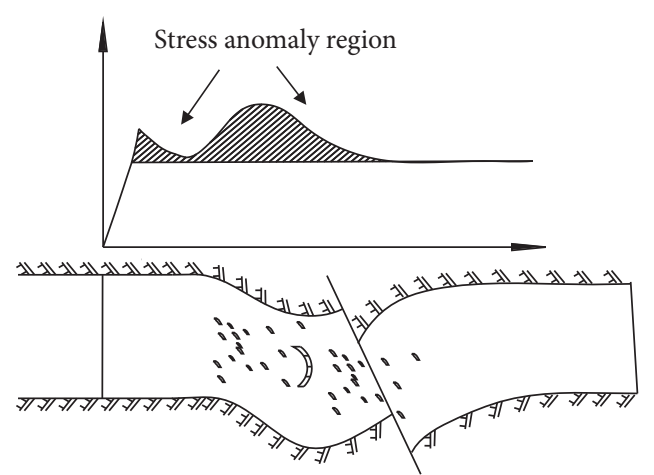

(b)

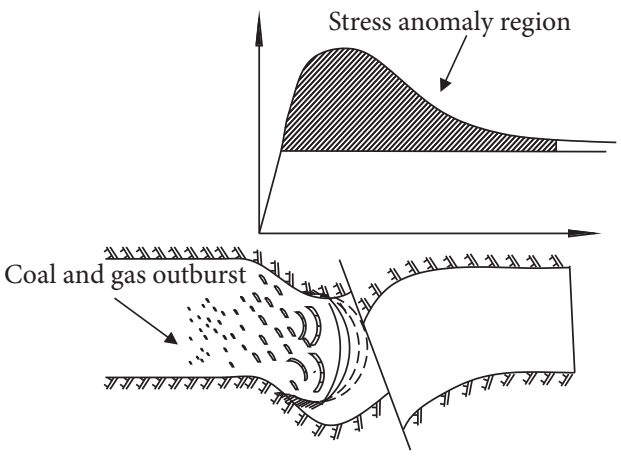

(d)

Figure 9: Evolution model of deep low gas dynamic disaster.

the mining operation destructs the mechanical balance in coal around the roadway. The strength, stress distribution, and gas pressure of coal in the coal seam are constantly changing, while the formed low-strength coal, abnormal stress distribution, and gas accumulated areas all provide a good breeding environment for the evolution of dynamic disasters in deep coal seams with low gas pressure.

(2) Formation stage: under deep mining conditions, coal is subjected to a higher stress and accumulates more elastic energy. At this time, the coal seam has stable stress distribution and is in its equilibrium. The presence of faults and similar geological structures breaks the original stress distribution, forming the stress concentration in the fault and construction area, which reaches the maximum near the fault. In the coal seam-mining process, the mining-formed plastic zone continues to near the structure-formed plastic zone. The mining stress and tectonic stress are superimposed on each other, causing the stress state of the coal seam to be changed and the original stress balance system in the coal-rock mass to be broken. When the stress exceeds the ultimate strength of the coal, the coal will crack.

(3) Expansion stage: the effect of gas on coal is generally divided into two aspects: the corrosive action of adsorbed gas on the skeleton of coal and the mechanical action of free gas on the skeleton of coal. Both adsorbed and free gases make the strength of coal decrease and its brittleness increase. Meanwhile, as a fluid, free gas flows in micropores and microcracks of coal, making coal more susceptible to tensile damage. The effect of gas on coal is also affected by stress. When coal has a lower fracture degree, the effect of the low gas content on coal is not obvious; when coal has a higher fracture degree, fine coal under gas pressure will migrate outward. Deep coal mines have higher ground stress and accumulate a large amount of energy, which can provide a sufficient power source for the occurrence of coal dynamic disasters. Under the joint action of both stress and gas, the deformation and fracture of coal ever increases. Only when the pressure of gas in coal meets the condition for blowing crushed coal, gasinduced dynamic disaster will outburst.

(4) End stage: after the occurrence of gas outburst and other dynamic disasters, coal accumulates massive elastic energy due to gas expansion, which cannot provide a sufficient power source for coal dynamic disasters, thus resulting in the termination of gas dynamic disasters. 


\section{Discussion}

4.1. The Joint Effect of Different In-Situ Stress and Different Gas Pressure. Figures 5 and 6, respectively, show the influence of ground stress on the maximum hoop stress under the same gas pressure and the influence of gas pressure on the maximum hoop stress under the same in-situ stress. In coal mine, the ground stress and gas pressure are usually different, so it is necessary to discuss the effect of different ground stress and gas pressure. For this reason, four sets of simulation values of gas pressure and ground stress are designed, which are shown in Table 1 . When the tensile strength of the coal sample is $1.15 \mathrm{MPa}$ in the experiment, the variation curves of maximum circular stress at the tip of the internal crack of the four coal samples with the crack angle are analyzed by equations (12), (14), and (17), as shown in Figure 10. It can be seen from Figure 10 that when the ground stress is $5 \mathrm{MPa}$ and the gas pressure is $0.1 \mathrm{MPa}$ (the black line), the crack angle range that can make the stress exceed the bearing capacity of the coal body is about $10^{\circ} \sim 40^{\circ}$. Therefore, only a small number of coal body cracks can expand, the damage area is small, and it is difficult to have no significant damage. When the ground stress is 15 $\mathrm{MPa}$ and the gas pressure is $1.5 \mathrm{MPa}$ (the orange line), the crack angle range that can make the stress exceed the bearing capacity of the coal body is about $0^{\circ} \sim 52^{\circ}$. When the ground stress is $30 \mathrm{MPa}$ and the gas pressure is $3 \mathrm{MPa}$ (the red line), although the ground stress exceeds the orange line, the crack angle range that can make the stress exceed the bearing capacity of the coal body is about $2^{\circ} \sim 49^{\circ}$ and the damage capacity is lower than the orange line. In conclusion, it is easy to explain the critical value of coal and gas disasters.

The larger in-situ stress in deep mine can fully break the coal body, and only a small gas pressure is needed to eject the broken coal body to generate dynamic phenomenon. However, the ground stress of the shallow mine is small, so it needs high gas pressure to break the coal body. Therefore, the effective gas critical value of coal and rock dynamic disaster early warning verified in the shallow part is not applicable to the deep mining mine, and the gas critical value of coal and rock dynamic disaster early warning in the deep mine should be smaller than that in the shallow mine [44-48].

\subsection{Analysis of the Causes of Excessive Gas Generation in Coal} and Gas Outburst Process. Coal and gas outburst is an extremely complicated mechanical process. It is generally believed that its development process is affected by comprehensive action of ground stress and gas [49]. Coal crack expansion is an inevitable step of coal and gas outburst [50]. In the process of coal and gas outburst, the amount of outburst gas is often much higher than the actual gas content of the prominent coal body, up to several tens or hundreds of times [51]. For example, the coal and gas outburst in the Daping Coal Mine in 2004 outbursts 1894 tons of rocks and about $25 \times 10^{4} \mathrm{~m}^{3}$ gas with average gas volume per ton of coal being $132 \mathrm{~m}^{3} / t$. In China, the measured gas content in the coal seam of medium and high-grade coal and anthracite
TABle 1: Modeling scheme.

\begin{tabular}{lcc}
\hline Number & Gas pressure $(\mathrm{MPa})$ & Load stress $(\mathrm{MPa})$ \\
\hline 1 & 0.1 & 5 \\
2 & 0.1 & 15 \\
3 & 1.5 & 15 \\
4 & 0.1 & 30 \\
\hline
\end{tabular}

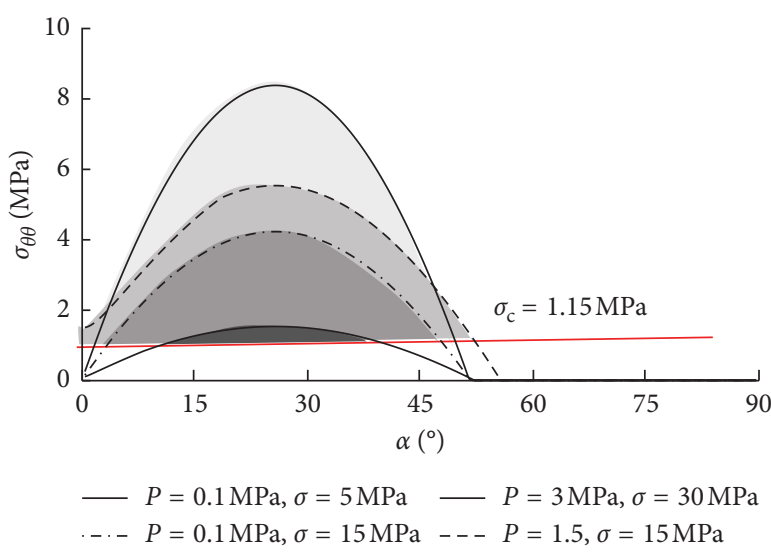

FIgURE 10: Variation of the maximum circular stress at the crack tip of four coal samples with the crack angle.

coal is $10-30 \mathrm{~m}^{3} / t$, with the highest of $36 \mathrm{~m}^{3} / t$, which is obviously lower than the amount of gas outburst [52]. Even considering the gas stored in the surrounding rocks in the process of gas production and gas outburst, the amount of gas present in the coal seam is far from being able to compensate for the difference between the gas content and the amount of Lan's adsorption.

Coal is a porous medium with pores and cracks, which contains a large number of macroscopic cracks and microscopic cracks and endogenous cracks and exogenous cracks [53]. In the process of coal formation, the gas generated per ton of coal is as high as $200-300 \mathrm{~m}^{3}$, most of which can dissipate through coal's porous and fracture systems, and only part of it remains in the coal seam. The porous system of the coal seam is divided into closed pores-fractures and connected fractures. Because of the extremely poor permeability of the coal matrix, there are high gas pressure gradient between the closed pore fracture and the connected fractures, which forms favorable conditions for storage of high-pressure gas inside the closed pores and fractures. The directly measured gas pressure is the gas pressure in the opened pores, which is much lower than that in the closed pores and fractures.

The deformation and failure of coal is the result of cracks and fractures development. The new-formed cracks will connect some pores and fractures. The volume of the pores and fractures will increase after coal damaged under load, which indicates that under the action of ground stress and gas pressure, part of closed fissures communicate with open fractures. The closed fissures inside the coal seam can be transformed into open fissures, and the internal gas may be involved in coal and gas outburst processes such as coal body 
crushing and throwing, which also explains that closedfracture cracking is connected with the coal's pore and fracture system to release the internal gas in coal and gas outburst process under the action of high ground stress and high gas pressure. Therefore, in the process of outburst, the amount of outburst gas is often much higher than the measured coal-gas content. In the process of outburst prediction, the amount of gas generated by the fractured coal should also be comprehensively investigated together with analyzing the total amount of gas.

\section{Conclusions}

Gas dynamic disasters are still one of the important research directions of safety science, and the frequency of occurrence is increasing, which poses a threat to the safety of miners' lives and property. It is beneficial for controlling the occurrence of disasters to reveal stress-gas coupling function and the occurrence law of gas dynamic disaster under the condition of deep mining. The main conclusions of this paper are as follows:

(1) The maximum circular stress at the crack tip showed a trend of decrease with the increase of the angle between the crack and the maximum principal stress and increases linearly with the increase of gas pressure and ground stress. The destructive capacity of increasing the same gas pressure on the coal body is about twice of that of the ground stress and had a negative power function relationship with the friction coefficient of coal.

(2) In the process of dynamic disaster, crack propagation and penetration of coal under the joint action of ground stress and gas pressure is an important gestation stage. The superposition of large tectonic stress and mining stress in the geological structural zone can cause crack expansion and penetration, leading to fully broken of the coal body, which is prone to dynamic phenomena.

(3) In the shallow mining process, small ground stress needs work together with a large gas pressure to make coal body cracks to expand and penetrate, resulting in dynamic disaster. When the mining extends to the deep ground, the large ground stress can initiate crack expansion. Thus, even under the action of lower gas pressure, it is also possible to break the coal body with reduced gas threshold of the dynamic phenomenon, which is prone to the occurrence of the dynamic phenomenon of the low index.

(4) There are a large number of closed fissures inside the coal body. The high-pressure gas existing inside the closed fissure is an important source of excess gas in the process of coal and gas outburst. Therefore, in the process of predicting coal and gas outburst, the amount of gas generated by coal body fragmentation should be also comprehensively investigated except analysis of the total amount of gas.

\section{Data Availability}

The data used to support the findings of this study are available from the corresponding author upon request.

\section{Conflicts of Interest}

The authors declare that they have no conflicts of interest.

\section{Acknowledgments}

This work was supported by the Systematic Project of Guangxi Key Laboratory of Disaster Prevention and Structural Safety (2019ZDK013), the Fundamental Research Funds for the Central Universities (FRF-TP-18-081A1), and the China Postdoctoral Science Foundation (2018M641201).

\section{References}

[1] B. Li, N. Li, E. Wang, X. Li, Y. Niu, and X. Zhang, "Characteristics of coal mining microseismic and blasting signals at Qianqiu coal mine," Environmental Earth Sciences, vol. 76, p. 722, 2017.

[2] L. Qiu, E. Wang, D. Song et al., "Measurement of the stress field of a tunnel through its rock EMR field of a tunnel through its rock EMR," Journal of Geophysics and Engineering, vol. 14, no. 4, pp. 949-959, 2017.

[3] T. L. Anderson, Fracture Mechanics: Fundamentals and Applications, CRC Press, Boca Raton, FL, USA, 2005.

[4] X. He, X. Liu, B. Nie, and D. Song, "FTIR and Raman spectroscopy characterization of functional groups in various rank coals," Fuel, vol. 206, pp. 555-563, 2017.

[5] A. Griffith, "VI the phenomena of rupture and flow in solids," Philosophical Transactions of the Royal Society of London. Series A, Containing Papers of a Mathematical or Physical Character, vol. 221, no. 582-593, pp. 163-198, 1921.

[6] C. H. Park and A. Bobet, "Crack initiation, propagation and coalescence from frictional flaws in uniaxial compression," Engineering Fracture Mechanics, vol. 77, no. 14, pp. 27272748, 2010.

[7] H. Lee and S. Jeon, "An experimental and numerical study of fracture coalescence in pre-cracked specimens under uniaxial compression," International Journal of Solids and Structures, vol. 48, no. 6, pp. 979-999, 2011.

[8] J. Reinoso, P. Durand, P. Budarapu, and M. Paggi, "Crack patterns in heterogenous rocks using a combined phase fieldcohesive interface modeling approach: a numerical study," Energies, vol. 12, no. 6, p. 965, 2019.

[9] D. Song, E. Wang, L. Qiu, H. Jia, P. Chen, and M. Wei, "Response of coal rock apparent resistivity to hydraulic fracturing process," Geomechanics and Engineering, vol. 14, no. 6, pp. 581-588, 2018.

[10] M. F. Ashby and S. D. Hallam, "The failure of brittle solids containing small cracks under compressive stress states," Acta Metallurgica, vol. 34, no. 3, pp. 497-510, 1986.

[11] H. Li, S. Shi, B. Lin, J. Lu, Q. Ye, Y. Lu et al., "Effects of microwave-assisted pyrolysis on the microstructure of bituminous coals," Energy, vol. 187, Article ID 115986, 2019.

[12] X. P. Zhou, H. Cheng, and Y. F. Feng, "An experimental study of crack coalescence behaviour in rock-like materials containing multiple flaws under uniaxial compression," Rock Mechanics and Rock Engineering, vol. 47, no. 6, pp. 1961-1986, 2014. 
[13] Y. Niu, Z. Li, E. Wang, R. Shen, Z. Cheng, X. Gao et al., "Study on characteristics of EP responsing to coal mining," Engineering Fracture Mechanics, vol. 224, Article ID 106780, 2020.

[14] B. Li, N. Li, E. Wang, X. Li, Z. Zhang, X. Zhang et al., "Discriminant Model of Coal Mining Microseismic and Blasting Signals Based on Waveform Characteristics," Shock and Vibration, vol. 2017, Article ID 6059239, 2017.

[15] C. Zou, L. N. Y. Wong, J. J. Loo, and B. S. Gan, "Different mechanical and cracking behaviors of single-flawed brittle gypsum specimens under dynamic and quasi-static loadings," Engineering Geology, vol. 201, pp. 71-84, 2016.

[16] C. H. Park and A. Bobet, "Crack coalescence in specimens with open and closed flaws: a comparison," International Journal of Rock Mechanics and Mining Sciences, vol. 46, no. 5, pp. 819-829, 2009.

[17] L. Qiu, D. Song, X. He, E. Wang et al., "Multifractal of electromagnetic waveform and spectrum about coal rock samples subjected to uniaxial compression," Fractals, 2020.

[18] L. Li, S. Yan, Q. Liu, and L. Yu, "Micro-and macroscopic study of crack propagation in coal: theoretical and experimental results and engineering practice," Journal of Geophysics and Engineering, vol. 15, no. 4, pp. 1706-1718, 2018.

[19] X. Kong, E. Wang, S. Li, H. Lin, Z. Zhang, and Y. Ju, "Dynamic mechanical characteristics and fracture mechanism of gasbearing coal based on SHPB experiments," Theoretical and Applied Fracture Mechanics, vol. 105, Article ID 102395, 2020.

[20] W. Zhao, Y. Cheng, P. Guo, K. Jin, Q. Tu, and H. Wang, "An analysis of the gas-solid plug flow formation: new insights into the coal failure process during coal and gas outbursts," Powder Technology, vol. 305, pp. 39-47, 2017.

[21] H. Chai, P. Cao, and Y. Zhao, "Implementation and application of constitutive model for damage evolution of fractured rock mass," Chinese Journal of Geotechnical Engineering, vol. 32, no. 7, pp. 1047-1053, 2010.

[22] J. Zuo, Y. Chen, and H. Song, "Evolution of pre-peak axial crack strain and nonlinear model for coal-rock combined body," Chinese Journal of Geotechnical Engineering, vol. 39, no. 9, pp. 1609-1615, 2017.

[23] H. Zhao, H. Zhang, and Z. Wang, "Study on effects of impact load on coal sample surface crack propagation characteristics," Journal of China University of Mining \& Technology, vol. 47, no. 2, pp. 280-288, 2018.

[24] T. He and L. Wang, "Research on damage evolution laws of rock-coal-rock combination based on particle discrete element model," Safety in Coal Mines, vol. 49, no. 7, pp. 205-208, 2018.

[25] S. Xie, F. Zhao, and C. Chen, "Breaking mechanics analysis on mining protective seam to prevent coal and gas outburst," Coal Science and Technology, vol. 4, pp. 22-25, 2007.

[26] Z. Wang, Y. Li, and R. Li, "Fault gas outburst in roadway and determination of critical thickness of prevention rock pillar," Chinese Journal of Underground Space and Engineering, vol. 11, no. 4, pp. 1060-1065, 2015.

[27] I. A. Fedorchenko and A. V. Fedorov, "Gas-dynamic stage of the coal and gas outburst with allowance for desorption," Journal of Mining Science, vol. 48, no. 1, pp. 15-26, 2012.

[28] K. Gao, Similar Simulation Test of Induce Coal and Gas Outburst during the Uncovering Tectonic Soft Coal by Crosscut, AnHui University of Science and Technology, Huainan, China, 2013.

[29] M. G. Xu, K. Q. Dong, and Y. C. Dong, "Mechanism of coal and gas outburst with microelement destruction," Joural of Xi'an University of Science and Technology, vol. 34, no. 3, pp. 249-254, 2014.
[30] W. Q. Zhang, Study on Mechanical Property of Soft Coal under Impact Load and its Effect to Coal and Gas Outbrst, AnHui University of Science and Technology, Huainan, China, 2015.

[31] H. Wang, B. Zhang, L. Yuan, G. Yu, and W. Wang, "Gas release characteristics in coal under different stresses and their impact on outbursts," Energies, vol. 11, no. 10, p. 2661, 2018.

[32] G. R. Irwin, "Analysis of stress and strains near the end of a crack extension force," Journal of Applied Mechanics, vol. 24, pp. 361-364, 1957.

[33] Y. L. Feng, "Study on surrounding rock stress distribution characteristics and sidewall failure mechanism of seam gateway," Coal Science and Technology, vol. 48, no. 1, pp. 183-191, 2018.

[34] J. Wang, Z. Wang, and S. Yang, "A coupled macro-and mesomechanical model for heterogeneous coal," International Journal of Rock Mechanics and Mining Sciences, vol. 94, pp. 64-81, 2017.

[35] F. Erdogan and G. C. Sih, "On the crack extension in plates under plane loading and transverse shear," Journal of Basic Engineering, vol. 85, no. 4, pp. 519-525, 1963.

[36] L. Qiu, Z. Li, E. Wang et al., "Characteristics and precursor information of electromagnetic signals of mining-induced coal and gas outburst," Journal of Loss Prevention in the Process Industries, vol. 54, pp. 206-215, 2018.

[37] Y. Niu, X. Song, Z. Li, E. Wang, Q. Liu, Z. Zhang et al., "Experimental study and field verification of stability monitoring of gas drainage borehole in mining coal seam," Journal of Petroleum Science and Engineering, Article ID 106985, 2020.

[38] J. Liu, Experimental Study on the Evolution Process and Mechanism of Coal and Gas Pressure, China University of Mining and Technology, Beijing, China, 2014.

[39] M. Gao, S. Zhang, J. Li, and H. Wang, "The dynamic failure mechanism of coal and gas outbursts and response mechanism of support structure," Thermal Science, vol. 23, no. Suppl.3, pp. 867-875, 2019.

[40] W. H. Song and H. W. Zhang, "Research on the mechanism of tectonic stress field evolution for coal and gas outburst," Applied Mechanics and Materials, vol. 325-326, pp. 13521356, 2013.

[41] T. Jia, Z. Feng, G. Wei, and Y. Ju, "Shear deformation of fold structures in coal measure strata and coal-gas outbursts: constraint and mechanism," Energy Exploration \& Exploitation, vol. 36, no. 2, pp. 185-203, 2018.

[42] W. Li, T. Ren, A. Busch et al., "Architecture, stress state and permeability of a fault zone in Jiulishan coal mine, China: implication for coal and gas outbursts," International Journal of Coal Geology, vol. 198, pp. 1-13, 2018.

[43] L. Qiu, D. Song, Z. Li, B. Liu, and J. Liu, "Research on AE and EMR response law of the driving face passing through the fault," Safety Science, vol. 117, pp. 184-193, 2019.

[44] Q. Tu, Y. Cheng, P. Guo, J. Jiang, L. Wang, and R. Zhang, "Experimental study of coal and gas outbursts related to gasenriched areas," Rock Mechanics and Rock Engineering, vol. 49, no. 9, pp. 3769-3781, 2016.

[45] J. Sobczyk, "A comparison of the influence of adsorbed gases on gas stresses leading to coal and gas outburst," Fuel, vol. 115, pp. 288-294, 2014.

[46] J. Cao, H. Sun, B. Wang et al., "A novel large-scale threedimensional apparatus to study mechanisms of coal and gas outburst," International Journal of Rock Mechanics and Mining Sciences, vol. 118, pp. 52-62, 2019.

[47] H. Li, Z. Feng, D. Zhao, and D. Duan, "Simulation experiment and acoustic emission study on coal and gas outburst," Rock 
Mechanics and Rock Engineering, vol. 50, no. 8, pp. 2193-2205, 2017.

[48] C. Zhang, J. Xu, G. Yin, S. Peng, Q. Li, and Y. Chen, "A novel large-scale multifunctional apparatus 21 to study the disaster dynamics and gas flow mechanism in coal mines," Rock Mechanics and Rock Engineering, vol. 52, no. 8, pp. 28892898, 2019.

[49] Q. Hu and G. Wen, Mechanical Mechanism of Coal and Gas Outburst, Science Press, Beijing, China, 2013.

[50] Z. Zhao and Y. Tan, "Study on the mechanism of crack propagation of coal under gas pressure," Mining Research and Development, vol. 6, pp. 37-39, 2008.

[51] B. B. Beamish and P. J. Crosdale, "Instantaneous outbursts in underground coal mines: an overview and association with coal type," International Journal of Coal Geology, vol. 35, no. $1-4$, pp. $27-55,1998$

[52] P. D. Gamson, B. B. Beamish, and D. P. Johnson, "Coal microstructure and micropermeability and their effects on natural gas recovery," Fuel, vol. 72, no. 1, pp. 87-99, 1993.

[53] Z. Feng and Y. Zhao, "Control of rock fissure scale on its deformation and failure," Chinese Journal of Rock Mechanics and Engineering, vol. 27, no. 1, pp. 78-83, 2007. 